\title{
PEMIKIRAN DEWI SARTIKA PADA TAHUN 1904-1947 DALAM PERSPEKTIF ISLAM
}

\author{
ELIS FAUJIAH* \\ elisfauziyah2500@gmail.com \\ SAMSUDIN* \\ samsudin@uinsgd.ac.id
}

*Fakultas Adab dan Humaniora UIN Sunan Gunung Djati Bandung

\begin{abstract}
ABSTRAK
Raden Dewi Sartika melanjutkan perjuangan dan gagasan Kartini dengan mendirikan Sekolah Kautamaan Istri di Bandung. Tulisan ini mencoba untuk mengutarakan pemikiran atau pandangan Raden Dewi Sartika dalam menjalankan agama islam. Untuk mendapat data yang valid, metode yang digunakan dalam penelitian ini adalah metode penelitian deskriptif. Penelitian ini dilakukan dengan beberapa teknik: pemilihan topik, pengumpulan sumber (heuristik), kritik intern dan ekstern (verifikasi), analisis dan interpretasi (penafsiran), dan penyajian dalam bentuk tulisan (Historiografi). Pemikiran Dewi sartika tak lepas dari pengaruh dari kondisi sosial dan budaya pada masa kolonial yang banyak merenggut hak-hak perempuan.
\end{abstract}

Kata Kunci: Dewi Sartika, permikiran, perempuan dalam Islam

\begin{abstract}
Raden Dewi Sartika continued Kartini's struggles and ideas by establishing the "Sakola Kautamaan Istri" in Bandung. This study tried to discover Raden Dewi Sartika's thoughts from an Islamic point of view. To obtain valid data, the method used in this research was descriptive. The study was carried out by using techniques: topic choice, source collection (heuristics), internal and external criticism (verification), analysis and interpretation, and presentation (historiography). Dewi Sartika's thoughts could not be separated from the socio-cultural conditions in the colonial period which took away a lot of women's rights, at the same time was influenced by the Islamic teachings.
\end{abstract}

Keywords: Dewi Sartika, thought, women in Islam

\section{PENDAHULUAN}

Dewi Sartika adalah simbol kebangkitan kesadaran perempuan atas harga dirinya. Ia berjuang agar kaumnya sejajar dengan lawan jenisnya. Sosok perempuan pejuang ini lahir di Cicalengka, kabupaten Bandung. Ia dikenal sebagai salah satu tokoh perintis pendidikan perempuan di tatar Sunda, dan atas jasa-jasanya, ia dianugerahi gelar pahlawan nasional oleh pemerintah Indonesia pada tahun 1966.
Dengan segala keterbatasan, ia mencoba mengembangkan diri dan keyakinannya. Ia sudah mengidam-idamkan sekolah sejak kecil. Kendati usulnya sempat ditentang, pada 16 Januari 1904, sekolah impiannya bisa terwujud di pendopo Kabupaten Bandung. Sekolah itu terus berkembang dan harus dipindah ke Jalan Ciguriang. Jalan ini selanjutnya dikenal orang sebagai Jalan Dewi Sartika. Namanya pun berubah jadi Sekolah Kaoetamaan Isteri, dengan cabang 
tersebar di Tasikmalaya, Sumedang, Cianjur, Ciamis, Kuningan, dan Sukabumi Ketika Kaoetamaan Isteri merayakan HUT-nya yang ke-35, Dewi dianugerahi gelar Orde van Oranje Nassau (Narasi, 2005).

Penelitian ini berfokus pada korelasi antara pemikiran Dewi Sartika dengan agama Islam. Tujuan penelitian ini adalah untuk mendeskripsikan perilaku Dewi Sartika dalam menjalankan kewajiban dalam agama Islam yang sekaligus telah memberikan sumbangsih yang amat besar terhadap nasib pendidikan perempuan Indonesia. Sejumlah literatur yang telah membahas Dewi Sartika, tetapi menurut penulis literatur tersebut kurang menunjukkan sisi keislaman. Pada masa itu Islamisasi di Pulau Jawa telah berkembang pesat dan telah ikut mempengaruhi gagasangagasan Dewi Sartika.

Dalam agama Islam, menuntut ilmu dan berpendidikan adalah sebuah kewajiban setiap manusia, baik perempuan ataupun laki-laki. Agama Islam menunjung tinggi nilai-nilai kemanusiaan, menghormati perempuan dan menjunjung tinggi hak-hak serta martabat perempuan, sehingga dalam agama Islam isu emansipasi perempuan atau feninisme bukan hanya sekadar teori belaka. Berangkat dari paparan yang disampaikan, penelitian ini dilakukan dengan mengangkat tema seorang tokoh pendidik perempuan berasal dari Tatar Sunda yang memiliki kepedulian dalam memajukan kaum perempuan di bidang pendidikan.

\section{METODE}

Metode yang digunakan dalam penelitian ini adalah metode penelitian sejarah. Langkah-langkahnya yaitu pemilihan topik, pengumpulan sumber, kritik intern dan ekstern, analisis dan interpretasi, dan penyajian dalam bentuk tulisan (Kuntowijoyo, 2018). Heuristik merupakan proses mencari dan menemukan sumber yang mana sumber yang digunakan adalah berupa studi kepustakaan. Data yang terdapat dalam penelitian ini dikategorikan data kualitatif dengan demikian teknik analisis data yang digunakan dalam penelitian ini adalah teknik analisis data kualitatif Sumber yang digunakan adalah sumber sekunder (Tanaga, 2019; Wiriaatmadja, 1986; Yaniar, 2004, dan literatur lainnya). Setelah proses pengumpulan sumber, dilakukan proses verifikasi atau kritik sumber. Tahapan berikutnya adalah tahapan interpretasi (Naseer \& Sulasman, 2018). Proses terakhir dalam metode penelitian sejarah disebut historiografi, yakni penulisan, laporan hasil penelitian sejarah yang telah dilakukan. Dalam historiografi ini hendaknya dapat memberikan gambaran proses penelitian dari awal sampai akhir yaitu penarikan kesimpulan.

\section{HASIL DAN PEMBAHASAN Biografi Dewi Sartika}

Dewi Sartika dilahirkan pada 4 Desember 1884 sebagai putri pertama dan anak kedua dari R. Rangga Somanagara, Patih Bandung. Ibunya R.A. Rajapermas, putri Bupati Bandung R.A.A. Wiranatakusumah IV, yang terkenal dengan sebutan Dalem Bintang (Wiriaatmadja, 1986). Dewi Sartika dibesarkan bersama saudarasaudaranya yaitu Raden Somamur, Raden Yunus, Raden Entis dan Raden Sari Pamerat. Ketika Dewi Sartika lahir, sang ayah belum menjadi Patih Bandung. Saat itu R. Rangga Somanagara baru memegang posisi Patih Afdeeling Mangunreja. Tujuh tahun kemudian, yaitu pada 1891, barulah ia dilantik menjadi patih Bandung yang jabatannya setara dengan wakil bupati. Sebagai 
seorang anak patih, Dewi Sartika mempunyai kehidupan sosial yang mapan, dalam kondisi sosial saat itu keluarga patih dikategorikan sebagai priyayi (Tanaga, 2019)

Dewi Sartika disekolahkan oleh ayahnya, meskipun saat itu pendidikan tidak lumrah untuk anak perempuan, dari golongan priyayi sekalipun. Sekolah kelas satu dibuka pemerintah Belanda bagi anak-anak priyayi yang berasal dari keluarga mampu. Sesudah dilakukan politik etis pada 1900, sekolah kelas satu dikembangkan menjadi Hollandsch Inlandshe School (HIS) atau sekolah dasar (Tanaga, 2019). HIS menggunakan bahasa Melayu sebagai bahasa pengantar bagi kelas bawah dan bahasa Belanda untuk kelas yang lebih tinggi serta kurikulumnya sesuai dengan Europeesche Lagere School (ELS) sekolah yang sederajat dengan HIS tetapi hanya berlaku bagi orang Eropa dan anak-anak Belanda.

Dewi Sartika belajar bahasa Belanda, Inggris dan ilmu yang lainnya saat sekolah di HIS, tetapi sayangnya pendidikannya harus terputus karena ayahnya dituduh melakukan percobaan pembunuhan terhadap bupati Bandung yang baru R.A.A. Martanagara. Saat pemilihan calon bupati Bandung, nama R. Rangga Somanagara tidak ada dalam daftar calon, padahal dia merupakan menantu dari Bupati sebelumnya, R.A.A. Kusumadilaga, dan telah menjalankan tugas bupati Bandung sementara sampai ditetapkannya bupati baru. Hal ini menyebabkan Somanagara diklaim sebagai orang yang memiliki alasan kuat untuk terlibat dalam peristiwa pemasangan dinamit pada pertengahan juli tahun 1893 saat pelantikan Martanagara.

Setelah pertikaian politik ini, Somanagara dibuang ke Ternate, dan Raden Ayu Rajapermas, ibu Dewi Sartika, memutuskan untuk ikut menemani suaminya (Zakiah, 2011). Hukuman ini juga disertai dengan penyitaan harta benda dan mengakibatkan keluarga Somanagara harus bergantung kepada orang lain.

Dewi Sartika dititipkan di rumah pamannya yang bernama Raden Demang Suria Kartahadiningrat atau Patih Aria Cicalengka. Patih ini terkenal sebagai tokoh yang disegani dan rumahnya dianggap sebagai tempat yang dihormati dan layak dijadikan teladan dalam tatacara kehidupan priyayi sehingga banyak perempuan lain yang merupakan anak priyayi, seperti putri wedana, camat, jaksa, dan pejabat-pejabat lainnya yang dititipkan di rumahnya (Wiriaatmadja, 1986). Di sana Dewi Sartika diperlakukan berbeda, dengan posisinya sebagai anak buangan membuatnya dikucilkan dan tidak disukai oleh kaum kerabatnya.

Pada masa remajanya itu, ia belajar pendidikan ala kadarnya seperti memasak, menjahit, memasang meja, melayani orang tua makan, menyulam dan sopan santun. Terkadang gadisgadis ini diberi pelajaran bahasa Belanda yang diajarkan oleh nyonya-nyonya Belanda yang tengah mengikuti suaminya bertugas atau gadis-gadis itu diantarkan ke rumah nyonya Belanda istri kontrolir dalam pengawasan yang ketat. Pengajaran ini biasanya tidak berjalan lama karena nyonya Belanda ikut suaminya yang dipindahkan atau gadis-gadis itu dijemput keluarganya untuk dinikahkan.

Hidup dalam suasana feodal yang mengekang, segala kesibukan kegiatan keperempuanan yang menghabiskan sebagian besar waktu tidak menambah wawasan para gadis. Seluruh minat dan harapan para gadis hanya tertuju pada satu tujuan yaitu pernikahan. Pada tahun 1902 Dewi Sartika meninggalkan 
Cicalengka dan pulang ke daerah asalnya Bandung. Alasan kepulangannya adalah ibunya telah kembali dari buangan karena ayahnya wafat.

Pada 16 Januari 1904 ia mendirikan sekolah khusus perempuan di pendopo Kabupaten Bandung. Sekolah itu terus berkembang dan harus dipindah ke Jalan Ciguriang. Jalan ini selanjutnya dikenal orang sebagai Jalan Dewi Sartika. Namanya pun berubah jadi Sekolah Kaoetamaan Istri, dengan cabangnya yang tersebar di Tasikmalaya, Sumedang, Cianjur, Ciamis, Kuningan, dan Sukabumi.

Pada tahun 1906 Dewi Sartika menikah dengan Raden Kanduruan Agah Suriawinata (Raden Agah), guru di Karang Pamulang. Ia adalah suami yang pengertian dan memberikan dukungan penuh terhadap pergerakan istrinya. Berkat bantuan suami yang setia inilah sekolahnya semakin maju dan bermutu (Ibrahim, 2018). Saat Perang Dunia I terjadi, sekolah yang dikelola Dewi Sartika mengalami kesulitan. Kemudian Nyonya Tijdeman dan Nyonya Hillen menulis surat pada pemerintah Hindia Belanda agar bersedia membantu "Sakola Kautamaan Istri". Pemerintah setuju. Maka pada 1929, sebuah gedung yang lebih besar dan lengkap dibangun. Untuk menghormati jasa Dewi sartika, nama "Sakola Kautamaan Istri" diubah namanya menjadi "Sakola Raden Dewi" (Yaniar, 2004).

Pada 25 Juli 1939, suami Dewi Sartika wafat. Ia sangat berduka atas kepergian suaminya tercinta dan sejak itu kesehatannya mulai menurun. Pada 1940, sekolah kembali mengalami kesulitan yang berat atas dampak dari meletusnya perang Dunia II disusul pendudukan Jepang (1942-1945). Pada 1947, Dewi Sartika terpaksa meninggalkan Bandung. Kegiatan sekolah pun berhenti sendirinya. Pagi hari, 11 September 1947, Dewi Sartika wafat Cineam, Tasikmalaya. Setelah Bandung kembali aman, sekolah Dewi Sartika dipinjam oleh pemerintah Indonesia untuk dipergunakan sebagai sekolah putri. Beberapa waktu kemudian sekolah dikembalikan pada Yayasan Dewi Sartika untuk menjadi sekolah yayasan putri. Makam Dewi Sartika kemudian dipindahkan dari Cineam ke Bandung (Yaniar, 2004).

\section{Latar Belakang Pemikiran Dewi Sartika}

Kedudukan perempuan dari zaman ke zaman dalam masyarakat Indonesia mengalami perubahan. Dulu perempuan pernah menduduki posisi yang cukup tinggi. Beberapa contohnya adalah Ratu Sima dari Kerajaan Keling, Tribhuwanatunggadewi dari wangsa Isyana, Suhita dari Majapahit dan Ratu Kalinyamat dalam sejarah Demak. Dari daerah-daerah lain terkenal nama Bundo Kandung dari Minangkabau, di Aceh pada abad ke-17 takhtanya pernah diduduki seorang perempuan, demikian juga di Sulawesi Selatan. Di desa-desa di Ambon, perempuan bisa memimpin dibantu oleh dewan desa, di Bali perempuan mendapat penghormatan kerajaan, dan di Kalimantan perempuan sanggup memerintah ((Wiriaatmadja, 1986).

Kemunduran kedudukan perempuan dalam masyarakat Sunda disebabkan oleh beberapa faktor. Faktor pertama, ketika zaman Kerajaan Mataram berkembang feodalisme dengan menempatkan istri sebagai lambang status seorang pria, perempuan yang awalnya adalah subjek tergeser kedudukannya menjadi objek. Kedua kedatangan agama Islam dan masyarakat salah memahami konsep perempuan dalam Islam, kebiasaan orang Arab yang menganggap 
perempuan lebih rendah daripada lakilaki dianggap sebagai ajaran Islam. Kemudian, adanya beberapa tradisi seperti perkawinan yang lebih condong merugikan perempuan, seperti kawin paksa, kawin gantung (pernikahan anakanak), penceraian secara sepihak, juga faktor perekonomian bangsa Indonesia yang mengalami kemerosotan di zaman kolonial terutama pada abad ke-19 yang berdampak pada kemerosotan umum khususnya di Jawa.

Hal ini terus belanjut hingga menimbulkan tradisi yang mengekang kaum perempuan, dampak yang terjadi dari pernikahan anak-anak dan tradisi lainnya sangatlah fatal. Nampak dari luar pasangan priyayi terlihat harmonis, pada kenyataannya banyak suami yang tidak mencintai istrinya, ataupun sebaliknya sehingga mereka mencari kesenangan di luar rumah. Pelacuran marak terjadi di mana-mana para perempuan priyayi rela meninggalkan anak suami demi mencari kebahagiann yang semu, laki-laki pun dengan seenaknya berpoligami tanpa memikirkan perasaan sang istri. Mengapa hal semacam ini bisa terjadi? Hal ini disebabkan kurangnya pengetahuan mengenai aturan agama Islam yang mengharamkan perzinahan atau bahkan mereka tidak diajari agama Islam sama sekali akibat adanya larangan diadakannya pelajaran agama Islam oleh pihak penguasa kolonial.

Dewi Sartika dapat merasakan langsung berada dalam lingkungan keluarga seperti ini, yaitu saat tinggal bersama keluarga pamannya di Cicalengka. Pamannya dengan seenaknya menikah, ia dapat melihat kesedihan dan rasa kesepian yang dialami oleh para perempuan di rumah itu. Berawal dari sinilah tercipta satu tekad kuat untuk melakukan emansipasi perempuan, ia berkeinginan untuk mendirikan sekolah perempuan dan mengajari pelajaran agama Islam, emansipasi perempuan lebih tepat diarahkan kepada peningkatan kerjasama itu dengan memberikan pemahaman dan kesadaran mengenai hak dan kewajiban masing-masing. Selain itu, pembelaan kepada kaum perempuan lebih diarahkan kepada penanaman nilai-nalai qur`ani terhadap mereka sehingga mereka terbebas dari gangguan yang dapat mengotori kesuciannya (Yusuf, 2017).

\section{Pemikiran Dewi Sartika dalam Pandangan Islam}

Segala gagasan dan pemikiran Dewi Sartika sejalur dengan ajaran Islam, meskipun tak banyak literatur yang menonjolkan hal ini. Namun, saat dihubungkan antara ajaran Islam dengan segala pemikiran Dewi Kartika maka kita akan menemukan titik temu keduanya.

Ketika Dewi Sartika melihat ketidakberdayaan ibunya yang tinggal oleh suaminya Somanagara. Ibunya yang saat itu bisa dijadikan gambaran seorang perempuan priyayi yang selama hidupnya hanya digunakan sebagai hiasan dan apabila tonggak penopangnya patah maka hancurlah bangunan tersebut. "Ari jadi awewe kudu sagala bisa ambeh bisa hirup" (menjadi perempuan harus memiliki banyak kecakapan agar mampu hidup) itulah kata-kata Dewi Sartika ketika melihat kondisi ibunya, yang membuatnya memberanikan diri untuk mengadap Martanagara dan menyampaikan keinginannya untuk membangun sekolah.

Muhammad Qutb menandai adanya dua pandangan mengenai konsep Islam tentang kedudukan perempuan, dan keduanya tidak sah. Pertama, pandangan yang mengatakan bahwa Islam telah memberikan hak-hak yang sama antara laki-laki dan 
perempuan dalam segala hal. Kedua, pandangan dengan penuh kejahilan menuduh bahwa Islam adalah musuh perempuan, Islam menjatuhkan taraf dan kehormatan perempuan, dan banyak lagi pernyataan yang sifatnya menyudutkan (pejoratif) terhadap Islam. Kedua pandangan tersebut menurut Qutb, dilatarbelakangi oleh ketidak pahaman mereka terhadap hakikat ajaran Islam dan dengan sengaja mereka mencampuradukkan antara kebenaran dan kebathilan (Abidin, 2017). Melihat pendapat tersebut kita bisa mengetahui bahwa masyarakat Nusantara telah salah paham mengenai kedudukan perempuan dalam agama Islam.

Saat meminta bantuan kepada Bupati Martanagara keinginan Dewi Sartika tidak langsung diterima, karena ia yakin dengan berdirinya sekolah khusus perempuan akan mendapat tantangan keras dari masyarakat. Konon katanya, "Entong awewe mah entong sakola asal bisa nutu-ngejo, bisa kekerod, bisa ngawulaan salaki, ngeus leuwih ti cukup, ganjaranna ge manjing sawarga. Komo ieu make jeung rek diajar bahasa Walanda sagala" (Jangan, perempuan tidak usah sekolah, asalkan bisa menanak nasi, menjahit, mengabdi kepada suami sudah lebih dari cukup, pahalanya surga. Apalagi mau belajar bahasa Belanda)

Namun, Dewi Sartika tetap teguh terhadap pendiriannya dan terus mengajukan permohonan hingga akhirnya hati Martanagara luluh dan mengatakan, "Nya atuh Uwi, ari Uwi panteg jeung keukeuh hayang mah, muga-muga bae dimakbul ku Allah nu ngawasa sakuliah alam, urang nyobanyoba nyieun sakola sakumaha kahayang Uwi. Pikeun nyegah bisi aya ka teu ngeunah di ahir, sakola teh hade lamun di pendopo wae heula. Lamun katangen henteu aya naon-naon, pek bae pindah ka tempat sejen" (Ya Uwi, jika Uwi sudah memiliki tekad yang bulat, semoga dimakbul oleh Allah yang menguasai seluruh alam, kita coba mendirikan sebagaimana yang dikehendaki oleh Uwi. Untuk mencegah hal-hal yang tidak diinginkan kemudian, lebih baik sekolah diselenggarakan di pendopo dahulu, apabila tidak terjadi apa-apa boleh pindah ke tempat lain).

Akhirnya sekolah impian Dewi Sartika bisa terwujud. Awalnya memang pandangan para priyayi mengenai sekolah ini sangatlah tidak baik, Dewi Sartika dianggap telah melanggar dan bertindak seperti bukan dari keturunan priyayi. Tetapi seiring berjalannya waktu para perempuan priyayi tersebut luluh, bahkan di antara mereka ada yang memberikan dukungan serta bantuan.

Selain memenuhi undangan ceramah, Dewi Sartika menyampaikan gagasan melalui berbagai tulisan. Banyak pemikiran menarik yang dituangkan Dewi Sartika melalui tulisan, salah satunya yang menjadi bahan pidato dalam perayaan tujuh tahun Sekolah Wanita. Dalam tulisan yang terdiri atas lima bagian tersebut, Dewi Sartika mengungkapkan banyak hal. Antara lain, ia mengungkapkan keinginannya menggerakkan pendidikan bagi perempuan bumiputra, kegelisahannya mengahadapi penolakan masyarakat, pendapat tentang generasi muda, perjuangan selama mengembangkan sekolah, pandangan tentang kehidupan, dan kerinduan meningkatkan derajat perempuan bumiputera setara dengan bangsa lain (Tanaga, 2019).

Awalnya Sakola istri ini terdiri dari dua puluh orang siswi dengan tiga guru yaitu Dewi Sartika sendiri, Nyi Poerwa, dan Nyi Oewid, tempatnya di ruang Paseban Barat, pendopo Kabupaten Bandung. Mengingat sekolahnya mengalami kemajuan yang 
pesat, jumlah muridnya bertambah banyak, sehingga ruangan tidak bisa menampung murid lagi. Oleh karena itu, akhirnya sekolah dipindahkan ke Jalan Ciguriang, Kebon Cau. Tahun 1909 sekolahnya meluluskan angkatan pertama. Saat itu pula bangunan sekolah direnovasi dan berganti nama menjadi "Sakola Kaoetamaan Istri". Pelajaran ditambah dengan pelajaran agama Islam, berhitung, bahasa Inggris dan Belanda serta ilmu kesehatan yang diajarkan oleh perawat Situsaeur bernama L. van Arkel (Ibrahim, 2018).

Cita-cita Dewi Sartika diketahui dari karangannya yang berjudul " $D e$ Inlandsche Vrouw" atau perempuan pribumi. Ia mengemukakan, pendidikan itu penting untuk mendapat kekuatan dan kesehatan anak, baik jasmani dan rohani. Setiap anak harus cageur bageur atau sehat rohani, jasmani, dan berkelakuan baik. Menurut Dewi Sartika, pendidikan penting bagi perempuan. Dewi menghendaki persamaan hak antara laki-laki dan perempuan (Yaniar, 2004). Dari sini dapat kita lihat bahwa tujuan dari gagasan serta perbuatan Dewi Sartika sebenarnya adalah bentuk jihad dalam Islam, ia bersungguhsungguh agar nasib perempuan Indonesia menjadi lebih baik, lebih memahami agamanya sendiri.

Adapun mengenai konteks Dewi Sartika yang tidak menyetujui seorang laki-laki berpoligami karena praktik tersebut bertentangan dengan aturan Islam. Seperti yang katan oleh Abdurrahman Al-Ghazaly, syariat Islam memperbolehkan poligami dengan batasan sampai empat orang dan mewajibkan berlaku adil kepada mereka, baik dalam urusan pangan, pakaian, tempat tinggal, serta lainnya yang bersifat kebendaan tanpa membedakan antara istri yang kaya dan istri yang miskin, yang berasal dari keturunan tinggi dengan yang rendah dari golongan bawah. Bila suami khawatir berbuat zalim dan tidak mampu memenuhi semua hak-hak mereka, maka hendaknya tidak berpoligami (Darmawijaya, 2015).

\section{KESIMPULAN}

Uraian di atas menjelaskan jejak langkah serta pemikiran Dewi Sartika dan proses merealisasikannya. Setelah dilakukan tinjauan pustaka dengan membandingkan beberapa literatur dapat disimpulkan bahwa gagasan Dewi Sartika selaras dengan ajaran Islam, beberapa gagasannya yaitu: (1) pentingnya pendidikan bagi perempuan; (2) emansipasi perempuan; (3) pandangannya tentang kehidupan, seperti sikap tidak setuju dengan praktik poligami dan perzinaan. Gagasangagasan ini mulai terlihat eksistensinya di permukaan setelah Dewi Sartika mendirikan Sekolah Kautamaan Istri pada tahun 1904 hingga meninggal pada 1947.

\section{DAFTAR PUSTAKA}

Abidin, Z. (2017). Kesetaraan Gender

Dan Emansipasi Perempuan Dalam

Pendidikan Islam. Tarbawiyah

Jurnal Ilmiah Pendidikan, 12, no. 1, 1-17.

Darmawijaya, E. (2015). POLIGAMI

DALAM HUKUM ISLAM DAN

HUKUM POSITIF (Tinjauan Hukum

Keluarga Turki, Tunisia Dan

Indonesia). Tarbawiyah Jurnal

Ilmiah Pendidikan, 1, no. 1.

Ibrahim, T. (2018). Manajemen 'Sekolah

Kaoetamaan Istri' Raden Dewi

Sartika Dalam Meningkatkan

Keterampilan Kaum Wanita Sunda.

Jurnal Manajemen Pendidikan Islam

Al-Idarah, 3 no. 1, 315.

http://www.ejurnal-

stitpringsewu.ac.id/index.php/JMPI 
/article/view/35

Kuntowijoyo. (2018). Pengantar Ilmu

Sejarah 1st ed. Tiara Wacana.

Narasi, T. (2005). 100 Tokoh Yang

Mengubah Indonesia. 1st ed. Vol. 27.

Penerbit Narasi.

Naseer, R., \& Sulasman. (2018).

Perkembangan Komunitas Arab Di

Indonesia: Studi Kasus

Perkampungan Masyarakat Arab Di

Pekojan Jakarta Barat Pada Tahun

1950-2018. Historia Madania, 15, no. $29,252$.

Tanaga, S. (2019). Ensiklopedi Tokoh

Nasional Dewi Sartia. 2nd ed.

Nuansa Cendekia.
Wiriaatmadja, R. (1986). Dewi Sartika. Departemen Pendidikan dan Kebudayaan.

Yaniar, R. (2004). Seri Pahlawan Nasional-Dewi Sartika. PT. Gramedia Widia Sarana.

Yusuf, K. M. (2017). Model Emansipasi Qur'Ani Terhadap Kaum Perempuan. Al-Fikra : Jurnal Ilmiah Keislaman, 11, no.1, 114. https://doi.org/10.24014/af.v11i1. 3855.

Zakiah, L. (2011). Konsep Pendidikan Perempuan Menurut Raden Dewi Sartika. Vol. 1. 